\title{
KEKERASAN SIMBOLIK TERHADAP KARAKTER HOMOSEKSUAL DALAM NOVEL LELAKI TERINDAH KARANGAN ANDREI AKSANA
}

Symbolic Violence against the Homosexual Characters in Andrei Aksana's Novel Lelaki Terindah

\author{
Desca Angelianawati \\ Universitas PGRI Yogyakarta \\ descang@upy.ac.id
}

Naskah diterima: 24 September 2019; direvisi: 25 Mei 2020 ; disetujui: 26 Juni 2020

DOI: $10.26499 /$ jentera.v9i1.1740

\begin{abstract}
Abstrak
Homoseksualitas selalu menjadi topik yang kontroversial di Indonesia karena Indonesia dianggap sebagai negara yang cukup konservatif terutama menyangkut preferensi seksual seseorang. Fenomena sosial ini tentunya bagi sebagian orang dianggap mengikat dan membatasi pilihan seksual seseorang. Dalam kaitannya dengan kesusastraan, tema homoseksualitas ini diangkat oleh beberapa novelis dalam karya sastra mereka, seperti Ayu Utami, Djenar Mahesa Ayu, dan Andrei Aksana. Novel Lelaki Terindah karya Andrei Aksana diambil sebagai obyek studi untuk penelitian ini dengan menganalisis (1) bentuk kekerasan simbolik dalam novel ini dan (2) bagaimana novel ini menentang heteronormativitas di Indonesia. Melalui metode studi pustaka, peneliti mendapati bahwa (1) bentuk kekerasan simbolik dalam novel Lelaki Terindah direpresentasikan dengan bentuk penormalan identitas seksual pada karakter LGBT. (2) Novel tersebut juga merupakan bentuk penentangan terhadap konsep heteronormativitas di Indonesia dengan menampilkan karakter LGBT dan mengangkat isu mengenai homoseksualitas yang ada di Indonesia.
\end{abstract}

Kata-kata Kunci: heteronormativitas, homoseksualitas, kekerasan simbolik

\begin{abstract}
Homosexuality is a controversial topic in Indonesia because Indonesia is considered as a conservative country concerning one's sexual preferences. This social phenomenon is binding as it restricts the identity construction of sexual preferences in Indonesia. Relating it to literary arena, this issue is addressed in several Indonesian literatures by Indonesian novelists like Ayu Utami, Djenar Mahesa Ayu, Ratih Kumala and Andrei Aksana. Taking Aksana's novel Lelaki Terindah as the object of the study, this paper analyses (1) how symbolic violence operates in the novel (2) how this novel resists the hetero-normativity in Indonesia. The library study is taken to deepen the analysis. The finding shows that (1) the form of symbolic violence is represented with the normalisation of the LGBT characters. (2) This novel also challenges the concept of Indonesian heteronormativity by representing the LGBT character and rising the issue about homosexuality in Indonesia.
\end{abstract}

Keywords: heteronormativity, homosexuality, symbolic violence

How to Cite: Desca Angelianawati. (2020). Kekerasan Simbolik Terhadap Karakter Homoseksual Dalam Novel Lelaki Terindah Karangan Andrei Aksana. Jentera: Jurnal Kajian Sastra, 9(1), 59-72. doi: 10.26499/jentera.v9i1.1740 


\section{PENDAHULUAN}

Jenis kelamin atau gender merupakan sesuatu yang tidak stabil atau tidak pasti serta lebih merupakan kontruksi sosial (Foucault, 1979; Diamond \& Butterworth, 2008). Berdasarkan kondisi tersebut terdapat banyak diskusi mengenai gender dengan fokus yang berbeda-beda. Bentuk susunan sosial dalam masyarakat dan budaya telah menciptakan peran gender dan argumentasi bahwa perbedaan dalam bersikap antara lelaki dan perempuan terletak pada konvensi sosial saja. Hal itu sesuai dengan pendapat Butler (1990) mengenai performativitas dari gender dan seksualitas.

Penelitian ini berfokus pada isu-isu kekerasan simbolik terhadap karakter kaum homoseksual di dalam novel. Seperti yang telah disebutkan bahwa homoseksualitas sebagai bagian dari seksualitas merupakan konstruksi gender. Namun, homoseksualitas di Indonesia masih tergolong hal yang tabu baik menurut pemerintah Indonesia maupun masyarakat pada umumnya. Terlebih lagi dengan adanya diskusi mengenai seksualitas di dalam konteks Indonesia yang kebanyakan selalu berputar di bahasan mengenai hubungan heteronormatif, hukum negara, hukum agama, kepercayaan, dan nilai adat (Blackwood, 1995; Angelianawati and Schmidt, 2017). Preferensi seksual yang dapat diterima di Indonesia adalah hubungan heteronormatif yang melibatkan lelaki dan perempuan. Prinsip hubungan heteronormatif yang ada di Indonesia tersebut diterima oleh khalayak umum karena dianggap bahwa mereka sesuai dengan kaidah norma pada umumnya. Mereka berpendapat bahwa pilihan seksualitas yang dianggap baik, normal dan natural idealnya haruslah heteroseksual, melibatkan perkawinan, monogami, dan sistem reproduksi. Sementara itu, seksualitas yang dianggap tidak baik adalah yang melibatkan perzinahan, homoseksualitas, dan sesuatu yang dikomersialkan (Rubin, 2011).

Dalam kaitannya dengan bentuk media kultural seperti literatur, isu mengenai prefensi seksual seseorang tersebut biasanya dibatasi oleh aturan bahwa mereka harus menjadi sesuai dengan kodratnya. Ditambah lagi novel-novel Indonesia yang mengambil karakter dari kaum homoseksualitas atau lesbian, kebanyakan berakhir dengan "penormalan" karakter untuk mengikuti kodrat mereka sebagai lelaki atau wanita seperti karakter yang ada dalam novel Nayla karangan Djenar Mahesa Ayu dan Saman karangan Ayu Utami. Dalam novel tersebut, karakter Nayla diceritakan sebagai seorang anak yang merindukan sosok seorang ayah dan tinggal dengan seorang ibu yang dominan. Hal ini membuatnya mencari pelarian dengan berpacaran dengan teman perempuannya yang bernama Juli. Keduanya terlibat dalam hubungan sesama jenis. Keduanya dianggap menyalahi kodrat sehingga untuk dapat 
diterima kembali dalam masyarakat Nayla harus kembali menjadi wanita normal serta meninggalkan identitasnya sebagai lesbian (Ayu, 2005). Hal yang sama juga terjadi kepada karakter Laila dalam novel Saman karangan Ayu Utami. Dalam novel tersebut, Laila diceritakan sebagai sosok gadis yang ingin memberikan keperawanannya kepada Sihar yang merupakan pacarnya. Shakuntala yang menjadi sahabat Laila bersedia membantu Laila dengan mengajari teknik dalam bercinta. Keduanya kemudian terlibat dalam hubungan sesama jenis tetapi pada akhirnya Laila kembali kepada kodratnya untuk menjadi wanita yang normal yang tertarik kepada lawan jenisnya (Utami, 2015).

Kesamaan yang didapat dari kedua novel tersebut adalah penormalan preferensi seksual seseorang berdasarkan norma yang diyakini oleh khalayak pada umumnya. Hal lain yang dapat digarisbawahi adalah hak individu dalam memilih orientasi seksual mereka telah menjadi bahan eksploitasi. Penormalan yang terjadi dan juga pembatasan dari preferensi seksual ini dapat menjadi contoh dari kekerasan simbolik seperti yang diutarakan oleh Pierre Bourdieu. Isu yang sama juga diangkat dalam novel Andrei Aksana berjudul Lelaki Terindah. Bentuk kekerasan simbolik dan pertentangan terhadap heteronormativitas di Indonesia yang menjadi fokus penelitian dapat terlihat dengan sangat jelas dalam novel ini yang akan dijelaskan lebih lanjut pada pembahasan.

\section{LANDASAN TEORI}

Untuk menjawab fokus penelitian secara lebih mendalam, peneliti menggunakan teori mengenai gender dan konsep kekerasan simbolik dari Pierre Bourdieu. Seperti yang disebutkan sebelumnya, penelitian ini membahas kekerasan simbolik terhadap karakter homoseksual dalam novel Andrei Aksana yang berjudul Lelaki Terindah dan bagaimana novel ini dapat memunculkan bentuk perlawanan terhadap heteronormativitas di Indonesia.

Potret homoseksualitas dalam novel ini juga merupakan sedikit cermin dari situasi dan kondisi yang dihadapi oleh komunitas LGBT di Indonesia. Seksualitas seseorang bagi sebagian besar masyarakat Indonesia masih dilihat sebagai suatu bentuk kodrat atau pemberian Tuhan yang harus dijaga dan dipelihara untuk kehormatan keluarga dan kelangsungan hidup bermasyarakat (Bennet, 2005). Cara tradisional untuk mudah melihat homoseksualitas dari kaca mata heteronormativitas adalah melalui sudut pandang bahwa lelaki seharusnya berpasangan dengan perempuan dan mengambil perempuan itu sebagai teman hidupnya. Akan tetapi, cara lain untuk melihat homoseksualitas melalui ranah gender adalah dengan melihatnya sebagai suatu bentuk konstruksi sosial (Butler, 1990). 
Seperti yang telah disebutkan sebelumnya, tingkat homophobia di Indonesia masihlah cukup tinggi. Sebagai ilustrasi, sistem hukum di Indonesia hanya mengenal dua jenis kelamin yaitu lelaki dan perempuan. Oleh karena konstruksi sosial yang ada tersebut, banyak masyarakat Indonesia yang masih menganggap bahwa kaum LGBT tidaklah wajar. Sebagai contohnya Undang-Undang Pornografi No. 44 tahun 2008 merepresentasikan pandangan negara terhadap aktifitas seksual yang dianggap menyimpang:

"Setiap orang dilarang memproduksi,...menyebarluaskan, menyiarkan,...menawarkan, memperjualbelikan menyewakan, atau menyediakan pornografi yang secara eksplisit memuat: persenggamaan, termasuk persenggamaan yang menyimpang, kekerasan seksual, masturbasi dan onani,...."

Undang-undang tersebut kemudian mengelaborasi devisi dari tindakan seksual yang menyimpang dengan penjelasan pada tiap babnya. Tindakan seksual menyimpang yang disebutkan di antaranya adalah bestiality, nekrofilia, oral, anal, lesbian, dan homoseksual.

Hukum negara tersebut bersinggungan dengan hukum adat utamanya hukum agama. Sebagai contoh fatwa yang dikeluarkan oleh Majelis Ulama Indonesia No. 57 pada akhir tahun 2014 menyebutkan:

"Bahwa sesuai fitrahnya, Allah SWT menciptakan manusia dan makhluk hidup berpasang-pasangan dan mengatur kecenderungan seksual didasarkan pasangannya..."

Dari fatwa tersebut dapat disimpulkan bahwa hubungan sesama jenis jelaslah merupakan tindakan yang menyimpang karena tidak sesuai dengan fitrah yang sudah ditetapkan. Hal ini tentunya berimbas kepada konstruksi sosial masyarakat mengenai homoseksualitas. Mereka akan cenderung menganggap homoseksualitas sebagai sesuatu yang menyimpang dan sebagai suatu bentuk penyakit. Dalam kaitannya dengan literatur, penormalan terhadap karakter LGBT dianggap sebagai salah satu solusi agar novel-novel bertemakan LGBT dapat diterima di tengah masyarakat.

Sementara itu, untuk memahami kekerasan simbolik, seseorang harus mengerti konsep disposisi dan habitus. Bourdie mendefinisikan disposisi sebagai segala sesuatu yang memicu praktek, persepsi, dan sikap tanpa terkordinasi dan diatur oleh peraturan apapun (Bourdieu, 2003). Disposisi ini sifatnya 'inculculated' (tertanam), 'structured' (terstruktur), 'durable (tahan lama), generatif, dan 'transposable' (merubah suatu tatanan). Secara singkat, habitus merupakan proses yang berangsur-angsur terjadi karena sesuatu yang ditanamkan secara terus menerus. Pengalaman masa kecil biasanya mempunyai peran yang sangat penting bagi proses ini. Melalui proses ini, suatu individu akan membentuk personalitas mereka sendiri. 
Disposisi-disposisi ini juga terstuktur, yang artinya mereka merefleksikan masyarakat dan kondisi sosial tempat mereka tinggal. Disposisi yang terstruktur ini nantinya akan terus ada selama kehidupan berlangsung dan beroperasi di bawah alam sadar seseorang. Disposisidisposisi ini nantinya juga bersikap generatif dan mampu mengubah suatu tatanan. Dengan kata lain, disposisi ini dapat menimbulkan suatu reaksi dan praktisi serta persepsi dari seseorang kepada yang lainnya.

Disposisi-disposisi ini nantinya akan membentuk suatu hal yang Bourdieu sebut sebagai habitus. Habitus adalah 'sekumpulan disposisi yang memunculkan suatu reaksi, praktek, atau persepsi di dalam badan baik itu pada kondisi yang normal ataupun tidak'. Diskusi mengenai habitus ini tidak dapat lepas dari relasi terhadap suatu konteks sosial tertentu yang Bourdieu sebut sebagai market atau kapital. Suatu kapital dibagi atas tiga bagian, yaitu kapital ekonomi, kapital kultural, dan kapital simbolis. Di antara ketiga kapital tersebut, kapital kultural dan kapital simbolilah yang berhubungan erat dengan diskusi mengenai homoseksualitas di Indonesia. Hal ini karena diskusi mengenai gender dan seksualitas termasuk homoseksualitas akan berkaitan erat dengan pemahaman, persepsi, pengetahuan, dan tingkat pendidikan seseorang.

Seperti yang disebutkan sebelumnya, masih banyak masyarakat Indonesia yang menganggap bahwa homoseksual adalah suatu penyakit. Hal ini bertentangan dengan pendapat Badan Kesehatan Dunia atau WHO yang sudah menghilangkan LGBT dari daftar penyakit mereka (Cochran, 2017). Hal yang sama juga terjadi di negara-negara yang dianggap lebih toleran terhadap LGBT seperti Thailand. Departemen Kesehatan Thailand bahkan sudah tidak lagi menganggap homoseksualitas sebagai penyakit mental (USAid Report, 2014). Di beberapa bagian negara-negara di Asia seperti di Taipei, preferensi seksual seseorang dirayakan seperti contohnya dengan adanya parade gay (Chang, 2017)

Kembali ke diskusi kekerasan simbolik, Bourdieu menambahkan bahwa kapital simbolik seperti prestise dan pangkat itu seperti suatu power yang esensial. Seseorang yang mempunyai kapital simbolik yang lebih besar biasanya akan menggunakannya kepada agen dengan kapital simbolik yang lebih kecil. Hubungan relasi antara dosen dan mahasiswa merupakan contoh dari hubungan kapital simbolik. Kekerasan simbolik terjadi apabila seseorang dengan kapital yang lebih sedikit menerima opresi yang diberikan oleh seseorang dengan kapital yang lebih besar. 
Satu hal yang patut digarisbawahi di sini adalah kenyataan di dalam masyarakat yang dicerminkan di dalam novel Andrei Aksana mengenai penerimaan homoseksualitas di Indonesia yang masih sangatlah sulit. Sanksi sosial dan adat seperti dikucilkan dalam masyarakat dan dipandang rendah membuat mereka mereka cenderung takut untuk terbuka mengenai preferensi seksual mereka. Sebagai akibatnya, mereka cenderung untuk merepresi pilihan seksual mereka dan menormalkan diri dengan berhubungan dengan lawan jenis sesuai dengan konsep hubungan heteronormativitas yang dapat diterima masyakarat pada umumnya (Boellstorf, 2005). Negara, adat, agama jelaslah mempunyai kapital yang lebih besar sehingga oknum LGBT harus menerima bentuk represi akan pembatasan seksual mereka tersebut (Boellstorf, 2007). Hal tersebut merupakan contoh dari konsep kekerasan simbolik seperti yang dikemukakan Bourdieu dan direpresentasikan dalam kebanyakan novel-novel Indonesia termasuk novel Lelaki Terindah ini. Penjelasan lebih lanjut mengenai manifestasi kekerasan simbolik akan ditulis di pembahasan.

\section{METODE PENELITIAN}

Objek penelitian dalam penelitian ini adalah novel Andrei Aksana yang berjudul Lelaki Terindah. Novel ini pertama kali diterbitkan oleh Gramedia Pustaka Utama pada tahun 2004. Metode yang digunakan adalah metode deskriptif-kualitatif karena data penelitian didapat dari analisa kata, wacana dan kalimat dalam novel. Studi pustaka dengan teknik pembacaan aktif dilakukan untuk mengumpullkan dan mengklasifikasi data.

\section{PEMBAHASAN}

Stigma tentang suatu hubungan yang heteronormatif biasanya telah tertanam sejak seseorang itu masih kanak-kanak. Dalam novel Lelaki Terindah karangan Andrei Aksana dijelaskan bahwa pengalaman masa kecil dapat terlihat jelas dalam karakter Valent. Dia telah mengalami banyak hal yang tidak mengenakkan ketika dia masih kanak-kanak. Kecelakaan telah merenggut nyawa ayahnya sehingga Valent tinggal bersama ibunya yang selalu berperan dominan dalam hidupnya. Ibu Valent tidak berpikir bahwa untuk membesarkan anak lelaki, dia membutuhkan suatu cara yang berbeda dari membesarkan anak perempuan. Dominasi dan pengalaman masa kecil inilah yang membuat perubahan dalam personalitas Valent terutama ketika dia mencapai masa pubertas.

Melewati usia kanak-kanak, Valent terkejut melihat perkembangan fisiknya. Tubuhnya berubah. Wajahnya berubah. Bahkan suaranya. la seperti tidak mengenali tubuhnya sendiri yang selama 
Kekerasan Simbolik Terhadap Karakter Homoseksual...

bertahun-tahun sebelumnya hidup di dalam diri Valent cilik. la seperti terkurung dalam hidup seorang lelaki dewasa.

Dominasi ibunya ditambah tidak hadirnya sosok seorang ayah dalam hidupnya, membuat Valent sering bertanya-tanya mengenai perubahan fisik terutama perubahan seksual dalam dirinya, "Mengapa di suatu malam ia terbangun dan mendapati celana dalamnya basah? Mengapa alat kelaminnya selalu mengeras di pagi hari?”

Valent sangat merindukan tidak hanya sosok seorang ayah, tetapi juga perhatian, cinta, dan pelukan dari seorang ayah. Dia tidak mempunyai figur laki-laki lain yang mampu dia jadikan panutan dalam hidupnya karena ibunya tidak menikah kembali dan dia merupakan anak tunggal. Dia menunggu datangnya seorang pria dalam hidupnya karena dia sangat berhasrat untuk mempunyai seorang figur lelaki tetapi dia takut. Dia mencoba untuk menyembunyikan ketertarikannya kepada sesama jenis karena dia merupakan anak tunggal dan dia berkewajiban untuk meneruskan garis keturunan keluarganya.

Dalam karakter Andrei Aksana yang lain, sosok Rafky juga merupakan contoh bagaimana pengalaman masa kecil itu membentuk karakter seseorang. Pada masa kanakkanaknya, Rafky selalu dihadapkan pada dominasi ayahnya. Sang Ayah menuntutnya untuk terus berhasil dalam semua bidang: olahraga, karate, bahkan ketika berpacaran dengan seorang gadis.

Perilaku Rafky tidak aneh, jauh dari penyimpangan. Seperti anak lelaki yang lain, Rafky enerjik dan aktif. la selalu suka berolahraga. la menyukai semua permainan yang menguras keringat dan tenaga...sejak kecil ia juga rutin latihan beladiri, karate dan taekwondo. (Aksana, 2004: 90)

Sebagai satu-satunya anak lelaki dalam keluarganya, Rafky tentulah dituntut untuk meneruskan garis keturunan keluarganya juga. Oleh karena itu, ketika dia bertemu Valent di pesawat menuju Bangkok, Thailand dan mulai tertarik dengan Valent secara seksual, dia mempertanyakan kewarasannya. Dalam benak Rafky, dia berpendapat, "Ia (Valent) bukan hanya tampan, ia cantik." Di sini, Rafky sudah mulai menganggap Valent, seorang lelaki lainnya sebagai seorang gadis. Oleh karena itu, dia berpendapat bahwa Valent itu cantik, kata yang lebih sering digunakan untuk menggambarkan seorang gadis daripada seorang lelaki. Hal ini kemungkinan juga merupakan bentuk refleksi dari diri Rafky yang tumbuh besar dengan ibu dan dua kakaknya. Dia terbiasa berada di tengah-tengah wanita. Oleh karena itu, kemungkinan besar, ketika dia merasakan ketertarikan sesama jenis terhadap 
Valent, secara tidak sadar, dia merepresentasikan dirinya sebagai seorang lelaki dan Valent sebagai seorang wanita.

Berdasarkan gambaran dari pengalaman kedua karakter penting dalam novel Lelaki Terindah ini, dapat terlihat dengan jelas bahwa pengalaman masa kecil juga berpengaruh dalam membentuk karakter kedua tokoh pria dalam novel ini. Pengalaman masa kecil itulah yang juga menuntun mereka untuk merasakan ketertarikan kepada sesama jenisnya. Dari sisi Valent, hal itu dimulai dengan tidak adanya sosok ayah dalam hidupnya, sementara dari sisi Rafky, hal tersebut dimulai dari hubungan yang gagal antara ayah yang dominan dan seorang anak. Hal ini sesuai dengan pendapat Nicolosi (1991) bahwa seseorang lelaki mencari kedekatan emosional dengan ayahnya melalui bentuk hubungan atau sikap homoseksual. Sementara itu, fiksasi dari gender yang telah menjadi stigma dalam masyarakat yang akan membuat mereka harus "'dinormalkan" agar sesuai dengan kodrat mereka. Seseorang yang tertarik dengan sesama jenisnya secara seksual akan dianggap tidak normal dan menyalahi kodratnya sebagai lelaki. Bourdieu (2003) menyebutnya sebagai doxa, yaitu kebenaran partikular yang dianggap sebagai kebenaran yang mutlak. Kekerasan simbolik dalam novel ini terjadi ketika kedua karakter merasa bahwa diri mereka "tidak normal" dan menyalahi kodrat karena mereka tertarik satu sama lainnya. Mereka merepresi keinginan mereka untuk embracing pilihan seksual mereka dan merasa bersalah karena mereka berbeda, karena tidak sesuai dengan apa yang dianggap 'normal' oleh masyarakat.

Manifestasi lainnya dari kekerasan simbolik ini dapat dilihat dari bahasan hubungan heteronormatifvitas yang ada di Indonesia dan terepresentasikan di novel ini. Berasal dari keluarga yang utuh dan dari Indonesia yang hanya menerima hubungan antara lelaki dan perempuan, Rafky merasa bahwa dirinya adalah seorang lelaki tulen. Dia harus menemukan seorang wanita untuk menjadi teman hidupnya. Oleh karena itu, ketika pada akhirnya dia berhubungan seksual dengan Valent, dia merasa, 'Rafky merasa jijik dengan dirinya karena bercinta dengan lelaki.' (Aksana, 87). Rafky merasa sangat bersalah dan merasa bahwa dia tidak cukup "lelaki." Sebagai efeknya, dia kemudian mencoba untuk berhubungan badan dengan seorang pelacur di Bangkok tetapi masih tidak bisa merasakan kepuasan dengan wanita itu.

"Rafky memejamkan matanya. Mencoba menikmati sentuhan dan cumbuan gadis itu. Gagal. la tidak merasakan apa-apa. Hatinya meronta mencari-cari apa yang salah. Rafky mengerahkan konsentrasinya kuat-kuat. Tapi justru bayangan itu yang berkelebat di sana. Wajah Valent yang tampan. (Aksana, 2004: 123) 
Kekerasan simbolik dalam bentuk hubungan normativitas membuat Rafky merasa bahwa dia "sakit" dan "menyimpang." Hal ini sesuai dengan pendapat Dede Oetomo (2001) yang menyebutkan bahwa seorang yang mengalami hubungan sejenis akan dianggap sebagai seseorang yang "sakit" dan "menyimpang" karena tidak sesuai dengan kodratnya. Bentuk kekerasan simbolik inilah yang menyebabkan kaum gay atau lesbian untuk susah mengakui bahwa mereka tertarik kepada sesama jenis kepada masyarakat umum. Hal ini mungkin menjadi sebab menapa masih terdapat kaum homoseksual di Indonesia yangdalam novel ini, Rafky dan Valent mencoba untuk "menormalisasikan" diri mereka dengan mengadakan double date-kencan ganda agar terlihat normal di mata khalayak umum. Kencan ganda mereka tidaklah sesukses yang mereka pkirkan. Mereka justru lebih merasa bersalah karena mereka tidak dapat mengakui preferensi seksual mereka kepada teman wanita tersebut. Mereka harus berhadapan tidak hanya dengan kedua wanita teman kencan mereka namun juga dengan keluarga dan masyarakat yang ada di Indonesia yang kebanyakan menentang hubungan sesama jenis. Hal ini terlihat ketika keluarga Rafky dan Valent menentang hubungan terlarang mereka. Valent yang akhirnya depresi harus dilarikan ke rumah sakit. Dia merasa sedikit sembuh ketika Rafky hadir di rumah sakit. Akan tetapi, opresi dari ibu dan teman wanitanya membuat kondisinya memburuk hingga dia pada akhirnya meninggal dunia.

Pada tingkatan ini sudah sangatlah jelas bahwa hubungan dan cinta sesama jenis menjadi tema penting dalam novel Lelaki Terindah karangan Andrei Aksana. Dalam hubungannya dengan konteks yang ada di Indonesia, novel ini tidak hanya merepresentasikan manifestasi dari kekerasan simbolik ketika oknum LGBT dalam novel tersebut dipaksa untuk mengingkari preferensi seksual mereka. Di samping itu, mereka juga dipaksa untuk "menormalkan" diri dengan kembali kepada fitrah mereka sebagai lelaki yang wajib untuk berhubungan dengan seorang perempuan.

Bentuk resistensi terhadap hubungan heteronormativitas yang ada di Indonesia juga ditunjukkan dengan sikap karakter homoseksual yang ada di novel tersebut terutama kepada karakter Rafky. Sesudah dia bercinta dengan Valent, dia mulai mengalami penolakan atas ketertarikan sesama jenis yang dia rasakan.

"Dan detik itu juga Rafky langsung memaki dirinya. Apa yang tengah terjadi? la lelaki normal! Tidak mungkin tertarik dengan sesama jenis! (Aksana, 2004: 35-36) 
Ketika Rafky merasakan ketertarikan seksual kepada Valent, dia mencoba meyakinkan dirinya sendiri bahwa dia masih normal. Sebagai lelaki normal, dia tidak mungkin tertarik kepada sesame lelaki. Dia bertanya-tanya kepada dirinya sendiri

"Mengapa aku terjerumus dalam hubungan cinta sejenis ini? Aku lelaki normal! Yang masih terangsang perempuan. (Aksana, 2004: 15)

Terlepas dari penolakan terhadap diri sendiri, penolakan atas preferensi seksual sesama jenis dalam novel ini juga ditunjukkan oleh ibunda Valent, Jenita. Setelah mengetahui bahwa Valent dan Rafky mempunyai hubungan sesama jenis, dia mulai lebih mendominasi hidup Valent. Dia secara tidak langsung membatasi gerak Valent agar tidak dapat bertemu Rafky. Bentuk pembatasan ini juga merupakan bentuk normalisasi terhadap kaum homoseksual.

"Kini setiap hari Valent diantar-jemput oleh supir pribadi Janita dan diawasi kegiatannya. Selesai jam kantor, harus langsung pulang ke rumah. Janita menghitung setiap menit. Valent tidak boleh terlambat sedetikpun. Janita seketat mungkin memonitor Valent agar anaknya tidak mempunyai celah untuk betermu Rafky. (Aksana, 2004: 169)

Dari teks tersebut dapat terlihat dengan jelas bahwa baik Rafky maupun Valent telah mengalami depresi emosional dan kekerasan simbolik tidak hanya dari keluarga tetapi juga dari masyarakat di sekitar mereka. Setelah mengakui bahwa mereka adalah pasangan sesama jenis, mereka mendapat perlakuan yang tidak menyenangkan dari orang-orang di sekeliling mereka. Gerak mereka dibatasi, hak mereka ditolak, dan pilihan mereka atas orientasi seksual mereka tidak diakui. Mereka mengalami diskriminasi karena orientasi seksual mereka. Hal ini sangatlah disayangkan karena sebagai manusia, mereka juga mempunyai hak untuk jatuh cinta dan memilih orientasi seksual mereka sendiri.

"Cinta...bukankah setiap orang berhak jatuh cinta? Seberapa pun nistanya, seberapapun hinanya..." (Aksana, 2004: 17)

"Apa cinta hanya milik laki-laki dan perempuan? Seharusnya cinta membebaskan semua batas!" (Aksana, 2004: 193)

Gambaran tentang percintaan sesama jenis yang ada di novel ini kemungkinan besar juga merupakan gambaran yang terjadi di masyarakat Indonesia. Rafky dan Valent dalam novel ini menjadi korban dari suatu hegemoni. Mereka dianggap sebagai orang yang "sakit" karena mempunyai hubungan di luar batas kewajaran. Seberapa pun baiknya, seorang homoseksual, dia biasanya akan dianggap sebagai seorang yang perlu dihukum dan dinormalisasikan. 
Kekerasan Simbolik Terhadap Karakter Homoseksual...

"Namun mengaku atau tidak mengaku, toh akhirnya tetap saja dihukum. Salah atau tidak salah. Begitu kan yang selalu terjadi? Kita hanyalah tumbal bagi orang yang telah berkuasa.

(Aksana, 2004: 144)

Melalui teks dalam novel tersebut, dapatlah terlihat jelas bahwa norma dan konsep heteronormativitas di masyarakat Indonesia itulah yang menjadi pembatas dan penghalang bagi kaum LGBT dalam menjalani hidup sesuai dengan orientasi seksual mereka. Satu hal yang patut diingat adalah bahwa mereka yang termasuk dalam kaum LGBT tersebut tidaklah meminta untuk dilahirkan secara "berbeda." Seseorang tidak bisa memaksa mereka untuk menjadi normal. Namun, dengan adanya wacana adat, agama dan hukum, hubungan sesama jenis menjadi hubungan yang kontroversial dan salah.

"Tapi, bukan cuma Mama yang menghalangi kita bersatu. Masyarakat, norma, dan hukum juga. Padahal apa salah kita? Kita tidak minta dilahirkan begini, bukan? (Aksana, 2004: 194)

Dari paragraf di atas, dapat dilihat bahwa bentuk kekerasan simbolik yang dialami oleh karakter LGBT dalam novel Andrei Aksana direpresentasikan dengan adanya penormalisasi dari karakter LGBT. Mereka dianggap aneh dan menyimpang oleh karenanya mereka harus kembali ke kodrat mereka sebagai seorang lelaki. Dihadapkan oleh norma dan adat yang berlaku, mereka tidak mempunyai pilihan lain kecuali untuk merepresi pilihan seksual mereka guna menjadi ormal' sesuai dengan standar norma yang ada di Indonesia pada umumnya.

Meskipun Indonesia merupakan negara sekuler, tetapi prinsip mengenai hubungan hetero yang sehat sesuai dengan hukum negara dan agama masih sangatlah kuat. Mekanisme seksualitas yang ada di Indonesia masih beriringan dengan hukum adat, hukum agama dan hukum negara (Robinson, 2001). Menurut ketiga hukum tersebut terutama hukum adat, secara universal, hubungan di luar hubungan hetero masih dilarang (Benner, 2005). Oleh karena itu, penyerangan dan tindak kekerasan terhadap kaum LGBT menunjukkan grafik yang terus meningkat (Dearden, 2017). Di beberapa tempat di negara barat, homoseksualitas dan kaum LGBT sudah mulai mendapat pengakuan dan kebebasan dalam menjalani preferensi seksual mereka, sedangkan kebanyakan negara di Asia khususnya Indonesia, negara dan adat masih berfokus pada hubungan hetero. Media Indonesia mulai menceritakan hubungan homoseksualitas semenjak tahun 1990 (Blackwood, 2007), tetapi banyak cendekiawan di Indonesia yang melihat bahwa media Indonesia masih cenderung untuk melihat homoseksualitas sebagai suatu kejahatan ataupun suatu penyakit yang harus 
disembuhkan. Sebagai hasilnya, masih banyak orang yang mengasosiasikan homoseksualitas dengan seks bebas, prostitusi dan persetubuhan (Gayatri, 1993).

Hal yang mengejutkan adalah kenaikan jumlah literatur fiksi Indonesia yang bertemakan LGBT sejak pertengahan tahun 2000 (Yulius, 2016). Fenomena ini mengonfirmasi pendapat bahwa resistensi itu erat hubungannya dengan opresi dan power (Foucault, 1998). Semakin banyak opresi yang dialami oleh oknum LGBT di Indonesia, maka akan semakin banyak pula simpatisan atau aktivis yang pro-LGBT yang menunjukkan resistensi mereka terutama lewat literatur.

Novel ini juga dapat disebut sebagai suatu bentuk resistensi melalui sirkulasi dan tema yang diangkat dalam kesusastraan Indonesia. Meskipun dalam sirkulasinya di Indonesia, novel Andre Aksana yang berjudul Lelaki Terindah ini tentulah harus disesuaikan dengan konteks yang ada di Indonesia agar dapat diterima oleh kebanyakan orang. Hubungan sesama jenis yang terlarang antara Rafky dan Valent menunjukkan sikap yang tidak sepantasnya bagi kebanyakan orang di Indonesia. Hal ini disebabkan juga karena tidak banyak orang yang mengerti dan memahami posisi seorang kaum LGBT di Indonesia.

Oleh karena itu, Lelaki Terindah karangan Andrei Aksana tidak hanya menunjukkan manifestasi atas kekerasan simbolik yang ada di Indonesia tetapi juga resistensi terhadap konsep hubungan heteronormatif yang masih kental di tengah masyarakat Indonesia. Kekerasan simbolik dalam novel ini dimanefestasikan melalui adat, agama dan negara yang tergolong sebagai "agen" dengan kapital yang lebih besar. Agen-agen ini cenderung mendominasi kaum LGBT yang mempunyai kapital yang lebih kecil. Hal ini memaksa kaum LGBT tersebut untuk tunduk terhadap aturan yang ditetapkan oleh agen-agen dengan kapital lebih besar.

Selain itu, novel ini yang menggambarkan kehidupan kaum LGBT di tengah masyarakat Indonesia yang masih tergolong homofobia. Dengan mengangkat isu dan menampilkan karakter homoseksual, novel ini dapat dikatakan sebagai bentuk resistensi terhadap sistem dan konsep hubungan heteronormativitas yang ada di Indonesia. Dengan peredarannya dan pemaparan akan kehidupan kaum homoseksual dan segala polemiknya, novel ini memaparkan bahwa setiap orang berhak atas pilihan hidupnya sendiri. Bentuk resistensi dari novel ini tidak hanya dapat dilihat dari penggambarannya, tetapi juga dari karakter LGBT yang ada di dalamnya. Valent, misalnya, tetap menjadi seorang lelaki homoseksual sampai saat dia meninggal. Rafky, karakter lain dalam novel ini juga masih tetap bertahan sebagai seorang lelaki homoseksual pada akhir cerita. 
Kekerasan Simbolik Terhadap Karakter Homoseksual...

\section{KESIMPULAN}

Novel Lelaki Terindah karangan Andrei Aksana ini sangatlah memperkaya literatur Indonesia dengan menawarkan perspektif yang baru kepada para pembacanya. Novel ini mengangkat isu mengenai homoseksualitas di Indonesia yang selalu menjadi topik kontroversial. Kaum homoseksualitas yang digambarkan di novel ini juga kemungkinan besar merepresentasikan kaum homoseksualitas lainnya di Indonesia yang sering mengalami kekerasan baik itu secara psikis, fisik atau simbolik. Narasi mengenai ketertarikan fisik dan emosional terhadap sesama jenis digambarkan dengan jelas di novel ini.

Dalam kaitannya dengan kekerasan simbolik, karakter homoseksual dalam novel ini juga telah mengalami kekerasan secara simbolik sejak mereka masih kanak-kanak. Ketika dewasa, mereka juga tidak mempunyai kebebasan dalam menentukan orientasi seksual mereka karena tinggal di masyarakat homofobia yang hanya menerima relasi antara lelaki dan perempuan saja. Kekerasan simbolik ini muncul ketika kedua tokoh homoseksual dalam novel Lelaki Terindah menerima kenyataan bahwa hubungan mereka merupakan hubungan yang sakit dan menerima label bahwa mereka memang menyimpang.

Di lain sisi, keberadaan novel yang mengusung tema tentang LGBT di Indonesia ini juga merupakan bentuk resistensi terhadap hubungan heteronormatif di Indonesia. Diskusi seksualitas yang hanya mengakui relasi antara perempuan dan lelaki serta yang selalu didasarkan kepada hukum adat, agama, norma dan hukum negara, mulai dipertanyakan dan dipertentangkan dengan kemanusiaan dalam novel ini. Seorang kaum homoseksual juga merupakan manusia yang mempunyai hak untuk menjalani kehidupannya sendiri termasuk memilih orientasi seksual mereka. Karakter yang terdapat dalam novel ini juga merupakan bentuk resistensi sendiri. Hal ini disebabkan karena mereka masih tetap berpegang pada pilihan mereka sebagai lelaki homoseksual pada akhir cerita.

\section{DAFTAR PUSTAKA}

Aksana, A. (2004). Lelaki Terindah. Jakarta: Gramedia Pustaka Umum Ayu, D.M. (2005). Nayla. Jakarta: Gramedia Pustaka Utama

Angelianawati, D and Schmidt, L. (2017). Discourses of Homosexuality on the Indonesian Television: HISKI Seminar Nasional Proceeding. Yogyakarta: Komisariat HISKI Sanata Dharma University, 2017, p. 24-28.

Badan Pengawas Keuangan dan Pembangunan (BPKP). "Undang-undang Republik Indonesia No. 44/2008 mengenai pornografi, p.2.” BPKP. Diambil dari sumber: http:/www.bpkp.go.id/uu/filedownload/2/33/151.bpkp pada tanggal 23 Juni 2020 
Badan Pengawas Keuangan dan Pembangunan (BPKP). "Undang-undang Republik Indonesia No. 44/2008 mengenai pornografi, p.10." BPKP. Diambil dari sumber: http://www.bpkp.go.id/uu/filedownload/2/33/151.bpkp. pada tanggal 23 Juni 2020

Bennet, L. (2005). Women, Islam and Modernity: Single Women, Sexuality and reproductive Health in Contemporary Indonesia. London: Routledge.

Blackwood, E. (1995). Senior Women, Model Mothers and Dutiful Wives: Managing Gender Contradictions in a Minangkabau Village. Berkeley: University of California Press.

Blackwood, E. (2007). Regulation of Sexuality in Indonesian Discourse: Normative gender, Criminal Law, and Shifting Strategies of Control. Indiana: Department of Sociology and Anthropology, Purdue Univ. Diambil dari sumber: Dx.doi.org, http://dx.doi.org/10.1080/13691050601120589 pada tanggal 23 Juni 2020

Butler, J. (1990). Gender Trouble: Feminism and the Subversion of Identity. NY: Routledge Classic.

Boellstorf, T. (2005) The Gay Archipelago: Sexuality and Nation in Indonesia. Priceton: Princeton Univ. Press.

Boellstorf, T. (2005) "The Emerge of Political Homophobia in Indonesia: Masculinity and National Belonging." Routledge Ethos Journal, vol 69:4, diambil dari sumber https://doi.org/10.1080/0014184042000302308. pada tanggal 23 Juni 2020

Boellstorf, T. (2007). A Coincidence of Desires: Anthropology, Queer Studies, Indonesia. Durham: Duke Univ. Press.

Bourdieu, P. (2003). Language and Symbolic Power. Massachusetts: Harvard University Press.

Chang, E. (2007). "Artist to participate in LGBTQ film festival parade." Artikel Bilingual terbit tanggal, 27 Oktober 2017.

Cochran. S. (2017). Proposed declassification of disease categories related to sexual orientation in the International Classification of diseases and related health problem. Geneva: Bulletin of World Health Organisation terbit tanggal17 Juni 2017. WHO International bulletin, diambil dari sumber: http://www.who.int/bulletin/volumes/92/9/14-135541.pdf pada tanggal 23 Juni 2020

Diamond, LM., \& Butterworth, M. (2008). Questioning Gender and Sexual Identity Over Time to Time. (Sex Roles: A Journal for Research Vol. 59)

Dearden, Lizzie. (2017). "Sharia Court in Indonesia Sentences Two Gay Men to 85 Lashes Each after being Caught Having Sex".https:/www.independent.co.uk/news/world/asia/islamiccourt-indonesia-gay-men-85-lashes-sex-caught-homosexuality-laws-first-time-khairil-jamala7740626.html diunduh pada tanggal 10 Agustus 2019.

Foucault, M. (1990). The History of Sexuality, vol. 1: An Introduction. Robert Hurley, trans. New York: Vintage Book

Foucault, M (1998). Power and knowledge. New York: Random House USA, Ic.

Gayatri, B.J.D. (1993). Coming Out but Remaining Hidden: Portrait of Lesbian in Java. Paper presented at the International Congress of Anthropological and Ethnological Sciences. Mexico: Mexico City.

Nicolosi, J. (1991). "Reparative Counseling of Male Homosexuality: A New Clinical Approach". Northvale, NJ: Jason Aronson. http://citeseerx.ist.psu.edu/viewdoc/download?doi=10.1.1.471.9777\&rep=rep1\&type=pdf diunduh pada tanggal 10 Agustus 2019.

Oetomo, D. (2001). "Giving the Voice to Those who Cannot Speak. Yogyakarta: Galang Press.

Robinson, K. (2001). "Gender, Islam, and Culture in Indonesia. Monash: Monash Asian Literature. Utami, A. (2015). Saman. Jakarta: Kepustakaan Populer Gramedia, 2015 
Kekerasan Simbolik Terhadap Karakter Homoseksual...

USAid Reports. (2014). "Being LGBTQ in Asia: Thailand country report." UNDP. Diambil dari sumber:https://www.usaid.gov/sites/default/files/documents/1861/Being_LGBTQ in_Asia Thailand_Country_Report.pdf pada tanggal 23 Juni 2020

USAid Reports. (2014). "Being LGBTQ in Asia: Indonesia country report." UNDP. Diambil dari http://www.asiapacific.undp.org/content/dam/rbap/docs/Research\%20\&\%20Publications/hiv aids/rbap-hhd-2014-blia-indonesia-country-report-english.pdf pada tanggal 23 Juni 2020

Yulius, H. (2016). Review: Queer Indonesian's constant search for home and belonging. An article written for Inside Indonesia. Diambil dari sumber https://www.insideindonesia.org/reviewqueer-indonesians-constant-search-for-home-and-belonging diunduh pada tanggal 10 Agustus 2019. 